\title{
Flawed science underlies laws on transgenic crops
}

\author{
United States needs a firm basis for commercialization, not a trade war with Europe.
}

Sir - Your News story "Trade war looms as US launches challenge over transgenic crops" describes the conflict between the United States and the European Union and reports questions over the labelling and traceability of transgenic crop products (Nature 423, 369; 2003). I would like to add that commercialization and cultivation of transgenic seeds are also in dispute.

The US government has often stated that its consent to large-scale commercialization was based on sound science, as required by the United Nations' Cartagena Protocol on Biosafety and other international agreements. However, examination of documents of the US agencies responsible, as well as confidential material, reveals a poor scientific basis for this decision ${ }^{1-3}$.

Two US National Research Council publications ${ }^{1,2}$ document the superficial and flawed nature of many scientific conclusions, revealing the lack of longterm risk assessment and of post-release monitoring. Superficial assumptions, poor experimental design and statistical flaws are also described in a report on insectresistant $\left(B t^{-}\right)$plants $^{3}$. The conclusion of a broad-scale analysis ${ }^{4}$ is that key experiments on both the environmental risks and benefits of genetically engineered plants are lacking.

In view of these deficiencies, a transgenic trade war seems ill-founded. Instead, the priority should be the generation of a sound scientific basis for registration of transgenic crop plants. Processes to be clarified at the laboratory and field levels include recombination and gene transfer events, as well as environmental selection processes that could cause resistance development and population shifts, with many potential secondary consequences.

\section{H. Sandermann Jr}

Institute for Biochemical Plant Pathology, GSF-National Research Centre for Environment and Health, D-85764 Neuherberg, Germany

1. National Research Council Genetically Modified Pest-Protected Plants: Science and Regulation (National Academies Press, Washington DC, 2000).

2. National Research Council Environmental Effects of Transgenic Plants: The Scope and Adequacy of Regulation (National

Academies Press, Washington DC, 2002 ).

3. Marvier, M. Am. Sci. 89, 160-167 (2001).

4. Wolfenbarger, L. L. \& Phifer, P. R. Science 290, 2088-2093 (2000).

\section{Getting to the heart of transpiration in plants}

Sir - Melvin T. Tyree in his Concepts essay on plant hydraulics "The ascent of water" (Nature 423, 923; 2003) mentions the wellknown comparison of the mammalian heart, the pump circulating the blood, to the movement of water in plants by "the pulling force generated at the evaporative surface of leaves" (transpiration). One interesting question arising from this comparison is whether transpiration is as essential for a plant as is the heart for an animal?

Although it is generally accepted that transpiration for plants is essential, doubts have often been raised. For example, Paul Kramer on page 293 of his book Water Relations of Plants (Academic, Orlando, 1983) states: "transpiration can be best regarded as an unavoidable evil" — unavoidable because no plant 'skin' has evolved that is permeable to $\mathrm{CO}_{2}$ but impermeable to water vapour. Which view is correct?

There are several distinct aspects to long-distance water transport. First, water lost via the evaporative surface of plant leaves has to be replenished to prevent the plant wilting, as outlined by Tyree. Second, 'growth water' has to be lifted to the top of plants (including trees) for the expansion growth of leaves, fruits and shoots. And third, all the water flowing downwards in the phloem has to be replaced by an equal volume of water moving upwards.

Only the water flow in the first of these is transpiration-driven. It does not take place if transpiration is zero or almost zero (if relative humidity is $100 \%$ or at night, when the stomata are closed). Evaporation generates a pulling force sufficient to replenish the amount of water lost by transpiration, thus minimizing the problem it creates for the plant.

The water movements caused by the second two processes do not depend on transpiration. The evaporative loss of, say, 100 molecules of water could at the very best generate a force sufficient to lift 100 molecules, but not 110 (those lost by evaporation plus those required for growth). So how is the amount of water in the second two processes moved against gravitational force? By the difference in water potential created by growth, volume flow of assimilates and root pressure. H. Beevers and I have estimated that in less than four days a negative water potential large enough to pull water up a 100 - $\mathrm{m}$ tree would arise in the absence of any transpiration (W.

Tanner and H. Beevers Proc. Natl Acad. Sci. USA 98, 9443-9447; 2001). Transpiration is not essential for net water movement: that is, the amount of water the plant requires. This calls into question the analogy with the mammalian heart. Widmar Tanner Lehrstuhl für Zellbiologie und Pflanzenphysiologie, Universität Regensburg, 93040 Regensburg, Germany

\section{Natural decaf could brew trouble for farmers}

Sir - The reduced-caffeine transgenic coffee plant (S. Ogita et al. Nature 423, 823; 2003) must be one of the first transgenic plants where a natural plant compound is suppressed. Caffeine has been proposed to form part of the plant's defence mechanisms, specifically against insects (J. A. Nathanson Science 226, 184-187; 1984) and slugs (R. Hollingsworth, J. Armstrong and E. Campbell Nature 417, 915-916; 2002). These transgenic plants may thus be more successful in testing this hypothesis than as an agricultural crop.

It is interesting that the transformation was carried out on Coffea canephora, the lower-grade robusta coffee, which has about twice as much caffeine as arabica has. As its name suggests, robusta is more resistant to attack by insects and diseases and it is likely that caffeine plays a role in that.

The coffee industry may be especially keen to reduce caffeine in robusta, as over the years it has gradually been slipping more of it into standard arabica blends. In the opinion of Ernesto Illy, chairman of the Institute for Scientific Information on Coffee and espresso maestro di tutti $i$ maestri, this has contributed to the present sluggish demand for coffee world-wide as consumers drink less to maintain a constant caffeine intake (Coffee and Cocoa International 28, no. 6, 20-22; 2001).

Because coffee is a perennial plant that takes about three years to come into production and may stay in the ground for 20 or more years, changing to a new variety is a major investment. Farmers would need assurance that the new plant is as resistant to attack as other varieties. Unfortunately, it could take many years for an agent to adapt to the new plant, so short-term tests might be insufficient. Further, coffee is grown in many regions and habitats, so very widespread field trials would be needed.

Hence, although a low-caffeine plant would be a useful research tool, there could be unintended long-term consequences most acutely felt by the poor farmer. P. S. Baker

Coffee Projects Coordinator, CABI Commodities, Bakeham Lane, Egham TW20 9TY, UK 